\title{
Routine healthcare for families in transition after a natural disaster ${ }^{1}$
}

\author{
Gisele Cristina Manfrini Fernandes² \\ Astrid Eggert Boehs ${ }^{3}$
}

\begin{abstract}
Objective: to present the healthcare routines of families in transition after natural disasters based on the Family Routines and Rituals theoretical framework. Method: this qualitative study of multiple cases was developed based on six rural families in southern Brazil, 2 years after a natural disaster. The data were collected through participant observation, interviews, narratives, genograms, ecomaps, and routine calendars, and a narrative analysis was conducted. Results: families showed notable episodes of illness that required professional assistance during post-disaster care, daily routine care, and other routines associated with healthcare services. Conclusion: these results reinforce the need for nurses to attend to family experiences during transitions after natural disasters and to prepare for the changes and needs with regard to healthcare and its promotion.
\end{abstract}

Descriptors: Nursing; Family Health; Health Promotion; Natural Disasters.

\footnotetext{
${ }^{1}$ Paper extracted from doctoral dissertation "Rotinas e rituais de cuidado de famílias rurais em transição inesperada do pós-desastre" presented to Centro de Ciências da Saúde, Universidade Federal de Santa Catarina, Florianópolis, SC, Brazil. Supported by Conselho Nacional de Desenvolvimento Científico e Tecnológico (CNPq).

${ }^{2} \mathrm{PhD}$, Professor, Fundação Universidade Regional de Blumenau, Blumenau, SC, Brazil.

${ }^{3}$ PhD, Associate Professor, Centro de Ciências da Saúde, Universidade Federal de Santa Catarina, Florianópolis, SC, Brazil.
}

Corresponding Author:

Astrid Eggert Boehs

Universidade Federal de Santa Catarina. Departamento de Enfermagem

Campus Universitário

Bairro: Trindade

CEP: 88040-900, Florianópolis, SC, Brasil

E-mail: astridboehs@hotmail.com 


\section{Introduction}

In 2008, the Vale do Itajaí in Santa Catarina, Brazil was the site of one of the most devastating regional natural disasters. The economic and social losses significantly changed the lives of numerous families in both the rural and urban areas of most municipalities. In one rural location in particular, flooding was associated with landslides that caused the loss of the homes and deaths of adults and children, resulting in unexpected transitions to their families. The community remained closed for a long period of time, and these families relocated to public shelters or the homes of family and friends. Healthcare facilities were also affected, which interfered with the local healthcare providers. As life changed after the disaster, issues emerged with regard to the routines of the families who faced the disaster, especially concerning healthcare promotion.

Although every natural disaster is unique depending on the affected areas and their different levels of vulnerability as well as the differences in social, economic, and health conditions, similarities exist and should be considered by nations in planning and attending to major issues ${ }^{(1)}$. In Brazil, floods are the most frequent type of natural disaster, and past occurrences in the south, southeast, and northeast regions have presented similar scenarios with respect to family life situations including stays in public shelters for months and delays in the reconstruction phase of the affected areas. During the reconstruction phase of the disaster cycle, several decisions and actions must be taken to return the context/environment to the normal situation as close as possible. The primary consideration is the time it takes to achieve such conditions ${ }^{(1)}$.

Moreover, the reconstruction period provides an opportunity to develop health mitigation programs and strengthen disaster preparedness programs. However, natural disaster preparation is practically nonexistent in Brazil, with a limited scope at the population, health professional, state, and municipality levels. Thus, it is necessary to discuss and consider the implications on the health and care of families who experience the disaster and its consequences.

The challenging experience of a disaster can cause health problems in the short and long terms, reinforcing its strong psychosocial and psychological effects on children, adolescents, women, and the elderly ${ }^{(2-8)}$. Nevertheless, only a few studies have dealt with the perspective of families affected by disasters, and little is known about the effects of this type of transition on the health and daily care of families in the long run. The theme of the 20th World Conference of the International Union for Health Promotion and Education (IUHPE) in July 2010 in Switzerland was Health, Equality, and Sustainable Development, and some studies $^{(9-11)}$ addressed the experiences of disasters and health promotion. The study conducted by Chinese nurses on a comprehensive program to promote the health of families during the rebuilding phase after a natural disaster in Taiwan should be noted. These authors mentioned using empowerment as a method to improve the skills of parents and children in the healthcare system and to rebuild their environment ${ }^{(9)}$. According to these authors, healthcare and promotion are linked to social and environmental resources, even during disaster situations in which the health of families can be affected and parental caregiving skills should be strengthened.

Family transitions can lead to stress, especially those that are not planned or expected. In certain situations, nurses may be in a unique position to establish a relationship of assistance that sufficiently provides necessary information, support, and resource mobilization during the stressful transitions that affect health. Given the complexities of life transitions, the capacity to promote health is a unique role for family nursing ${ }^{(12)}$.

According to a theoretical model of nursing, domestic health production is a socially constructed process $^{(13)}$ in which family routines and rituals are important routes through which nurses can discuss healthy practices, behaviors, and knowledge with family members to identify family goals, create plans to achieve well-being, or start the process of becoming healthier. Routines also provide necessary care strategies during acute or chronic diseases to protect and promote health, especially that of children ${ }^{(14)}$. This study presents the healthcare routines of families in transition after a natural disaster, based on the Family Routines and Rituals benchmark.

\section{Methods}

This qualitative study of multiple cases was developed with six families who experienced a natural disaster in a rural area of southern Brazil in 2008. The criteria used to choose the families were a residence in the area affected by the natural disaster and the presence of at least one child between 0 and 12 years old. 
The data collection was conducted between January and September 2010, 13 months after the disaster when the families were located in their homes with the help of the local family health staff. A brief description of the characteristics of each family who participated in the study is shown in Figure 1 below.

\begin{tabular}{|c|c|c|c|c|}
\hline Family composition & Education & Occupancy & Income & Damage \\
\hline $\begin{array}{l}\text { F1: A couple and their two school-age } \\
\text { daughters }\end{array}$ & $\begin{array}{l}\text { Incomplete elementary education } \\
1 \text { st and } 5 \text { th grade students }\end{array}$ & $\begin{array}{l}\text { General assistant and } \\
\text { farmer } \\
\text { Seamstress }\end{array}$ & $\begin{array}{l}\text { Two minimum } \\
\text { wages }\end{array}$ & $\begin{array}{l}\text { Total destruction of } \\
\text { housing; unemployment }\end{array}$ \\
\hline $\begin{array}{l}\text { F2: One couple, one preschool- } \\
\text { age child, an adopted school-age } \\
\text { daughter, and two adolescent } \\
\text { daughters, one of whom was married }\end{array}$ & $\begin{array}{l}\text { Incomplete elementary education } \\
\text { Incomplete secondary education } \\
\text { (adolescent) }\end{array}$ & $\begin{array}{l}\text { Mason and stay-at- } \\
\text { home mother } \\
\text { Seamstresses } \\
\text { (adolescent) }\end{array}$ & $\begin{array}{l}\text { Approximately three } \\
\text { minimum wages }\end{array}$ & $\begin{array}{l}\text { Destruction of housing } \\
\text { and land; unemployment }\end{array}$ \\
\hline $\begin{array}{l}\text { F3: One couple, one preschool-age } \\
\text { child, one school-age child, and a } \\
\text { cohabitating, adolescent daughter }\end{array}$ & $\begin{array}{l}\text { Incomplete elementary education } \\
\text { Elementary school (adolescent) }\end{array}$ & $\begin{array}{l}\text { Self-employed } \\
\text { (home production of } \\
\text { appetizers) } \\
\text { Seamstress } \\
\text { (adolescent) }\end{array}$ & $\begin{array}{l}\text { Approximately two } \\
\text { minimum wages }\end{array}$ & Material housing losses \\
\hline $\begin{array}{l}\text { F4: A couple and their adopted } \\
\text { school-age daughter }\end{array}$ & $\begin{array}{l}\text { Complete elementary education } \\
\text { Complete secondary education }\end{array}$ & Farmers & $\begin{array}{l}\text { Five minimum } \\
\text { wages }\end{array}$ & $\begin{array}{l}\text { Deaths in the family; } \\
\text { agricultural production } \\
\text { loss }\end{array}$ \\
\hline $\begin{array}{l}\text { F5: One couple, two school-age } \\
\text { children, and an adolescent son }\end{array}$ & $\begin{array}{l}\text { Incomplete elementary education; } \\
1^{\text {st }} \text { and } 5^{\text {th }} \text { grade students } \\
\text { Complete elementary education } \\
\text { (adolescent). }\end{array}$ & $\begin{array}{l}\text { Packers at a local } \\
\text { factory, including the } \\
\text { adolescent0 }\end{array}$ & $\begin{array}{l}\text { Five to six minimum } \\
\text { wages }\end{array}$ & $\begin{array}{l}\text { Destruction of housing; } \\
\text { unemployment }\end{array}$ \\
\hline F6: A mother and a nursing child & Complete secondary education & $\begin{array}{l}\text { Industrial machine } \\
\text { operator }\end{array}$ & $\begin{array}{l}\text { Approximately three } \\
\text { minimum wages }\end{array}$ & $\begin{array}{l}\text { Material losses; } \\
\text { unemployment }\end{array}$ \\
\hline
\end{tabular}

Figure 1 - General characteristics of the families who participated in this study

The narratives were produced within the specific family life context for each case because they represented distinct phases of development ${ }^{(15)}$ : couples with children, adolescents who were maturing (one of whom had married and left her parental home), and other distinct situations with regard to life after the disaster. Participant observational techniques were used during meetings at the households to collect data. Records were annotated in field diaries, narrative interviews were improvised ${ }^{(16)}$, and instruments such as the genogram and the ecomap were applied, and a routines calendar was supplied to the family members to write down their daily and weekly routines. The collected data were recorded with permission and transcribed by the researcher. The genogram and ecomap were constructed with the adult members of the families.

The joint construction of the genogram and ecomap also involved the spouses in each family, and the data collected measured the effect of the disaster on the extended family because more than one member was affected given they lived in close proximity within the rural disaster area. The ecomap furnished information concerning the major social resources available to the families, both formal (e.g., non-governmental and governmental organizations as well as the fire department) and informal (e.g., neighbors and extended family). Because the narratives regarding family relationships were built through the application of the genogram and ecomap, family rituals were remembered and maintained by the interviewees during the interview and deepened by the researcher.

The narrative analysis followed the steps proposed by Fritz Schütze, creator of the autobiographical narrative interview method and improvised narrative analysis. The first step consists of the formal analysis of the text in which all narrative passages were selected, using the formal indicators of initialization and the completion of each segment as reference. In the second step, the structural description of the contents of each previously selected narrative were used to identify elements of the interpretation of the narrated stories called the "procedural structures of the life course". To perform the third step, analytical abstraction, it was necessary to 
detach the details of each narrative segment and attend to the whole story, ordering the narrative segments by the stages of life or the narrated event and interpreting the abstract expressions of each stage with regard to each other based on the theoretical framework and the research goals. The fourth step, knowledge analysis, explored the non-indexed components of the stories: the argumentative narrative passages, the theoretical explanations of the informants about their life course (i.e., disaster experience) or their identities (theories about the self), comparative analyses, and backgrounds. It is at this stage that the researcher pays closer attention to the participants' interpretations. The fifth step consists of contrastive comparisons among the analytical categories found in the analysis of the different interviews of each family, searching for similarities and contrasts that favored comparisons among the participants themselves ${ }^{(16)}$.

The Committee on Ethics in Human Research approved the present study, Protocol \#490/2009. The confidentiality of the informants was respected, and participation in the research was agreed upon after signing the informed consent form (ICF).

\section{Results and Discussion}

The analysis category "healthcare routines" expresses the familial narratives concerning their perceptions of health after the disaster and the actions that promoted domestic health, such as child care in situations of illness.

\section{Changes in the family care routines and episodes of illness after the disaster}

The families narrated the illness episodes of specific members of either their nuclear family or extended family that represented dramatic events, which were emphasized at specific times after the disaster. In particular, when illness affected children, their parents related such occurrences as unexpected changes to the family routine, which were portrayed as worse than the duration spent in the shelters. The following excerpt illustrates this finding.

He was very sick from a sore throat [...] we got very wet, and he got wet and very sick. We had to take him to the hospital (-). I thought he was going to die [...]. Then the doctor looked at his little hand and said, "My God, this boy is lacking oxygen." He stayed a couple of days [at the hospital] on oxygen. That day in the hospital, I collapsed. I had not cried yet during the tragedy, [but] I cried that day [...]. That day was difficult. The doctor was very nice and told me, "Mom, take care of yourself because your son will be okay". (MF2)

The interruption in daily routines (e.g., those related to children's school attendance, parents' work, mealtimes, and bedtime), the noisy and cold environments for rest, and the idleness of adults affected the organization of care and were reflected in episodes of illness that required professional intervention and were perceived as health risks by the families. Children are naturally dependent on their routines and families; therefore, more exposure to the disaster increased negative health effects. Significant disruptions in their lives brought on by absence from their schools, homes, and communities or the death of family members or friends can seriously affect and cause psychological problems among children. Routine restoration is a priority after disasters as are intervention efforts to restore an apparent sense of normality and involvement with the local culture (when families are displaced) through sustainable programs or actions ${ }^{(3)}$. In addition, studies have shown that the predictability of routines influence the overall health of children and adolescents after considering health behaviors, family activities, family support, and the number of activities in which one or both parents are engaged or present ${ }^{(17)}$.

The sequence of narratives of Family 3 (F3) exemplifies care routines that changed after a long stay at the shelter. The lack of routine and the consumption of unhealthy foods affected the children's diets during the months that the family stayed in the collective shelter and persisted after they returned to their housing after the disaster.

At the shelter, we were with our two-year-old boy [...]. He was sick every day. We slept on a mattress on the floor (-) at the school, so everything was wet, and my son had pneumonia when he was little [...]. He became allergic to everything: It was horrible! He got so skinny, [he was] skin and bones [...]. My older son just cried too, he didn't want to study anymore (MF3). I cried every day because I wanted to go back (6-yearold child). They didn't want to eat (PF3). A lot has changed for him [referring to the 4-year-old son] (MF3.1). There was no dinnertime, no lunchtime, no breakfast time (-); nothing was certain. If you ate today at 6, maybe tomorrow would have to eat at 7 (-); then, the adults would eat but not the children (-). They only ate junk food and that pile of yogurt, juice, and chocolate (PF3.1). But at the shelter they were very kind to us because if there was some allergic reaction at night, we called them and they came to see [us], [and] would bring us medication (MF3.1). 
[...] I think for the family to be healthy, it is necessary to have a good diet, hygiene, [and] no vices, just in case (PF3). And one more thing that we do [that] ends up hurting the children is buying a lot of stuffed cookies and such things [...]. We have to take care not to harm their health (MF3).

Thus, the lack of parental autonomy regarding the choice and preparation of food offered to their children at the collective shelter negatively influenced the feeding routines of the children and adults after the disaster.

The appearance of physical symptoms as well as fear, depression, insomnia, and other emotions unveiled the stress experienced by family members, which was caused by the losses during the tragedy and the difficulties associated with starting over. In the context narrated by the families, the consequences of the traumatic event affected their health in different ways, given the individual and cultural aspects needed to cope with the situation and the professional care they received after the disaster.

Especially in the beginning, my husband had a blood pressure problem reaching $260 \times 130 \mathrm{mmHg}$. He does not have diabetes, but his blood glucose skyrocketed [...]. He was in the hospital, and the doctor said it was because of the stress. The tragedy happened in November, and this [medical scare] happened in February. In my case, the issue was not being able to sleep; he was up all night [...]. I also had hair loss, and I thought that I would go bald. Then I also went to the doctor. I talked to him, and he said, "This is emotional; the stress of the moment." I went back, and he prescribed a natural sedative; but then when I got home, I thought, "No, I'll try to handle this myself." I do not like to take medicine because I'm too afraid of becoming dependent on it, and so I just left the prescription there in the corner. But of course, there are days when we remember more and I end up not sleeping, especially during heavy rains or when it starts to rain at night; then the memories all come back. This is normal, I guess, because of what we have been through, right? So, this part was affected, the emotional part was very affected. But my husband and I tried to cope with it, without having to take a lot of medication [...]. Until now, my father took a large amount of medicine: sleeping medicine, stress medicine, high blood pressure medicine (-); he started a heart treatment, but he never had this problem before. My father's health was very much affected. My sister also started taking sleeping medicine a month ago (MF4).

The results of some studies have suggested that natural disasters can have long lasting effects on physical and mental health(18) as well as and on the use of primary healthcare services by the affected community throughout the following $\operatorname{year}^{(7)}$ given that the anniversaries of the event can be particularly traumatic, especially for those who have experienced losses. The grieving process for unexpected losses during a disaster can be complicated, thereby affecting the mobilization of coping mechanisms and stress management causing severe physical, psychological, and emotional manifestations that hinder motivation for specific daily activities ${ }^{(18)}$. Studies have also examined the experience of the disaster on the health of the elderly who are more vulnerable and more likely to die during this type of event. After Hurricane Katrina in New Orleans (USA) was followed by flood, psychological problems also affected the health of the elderly: Postdisaster mortality was also due to the chronic problems exacerbated by the evacuation process ${ }^{(8)}$.

Pregnant and lactating women have unique concerns with regard to natural disasters, particularly with regard to interruptions in their supply of clean water for drinking or bathing, insufficient access to food, security, and the interruption in healthcare services due to the conditions of the temporary shelter and the losses in the public health services (for prenatal care, child health, and so on). Hurricane Katrina affected and placed this population at great health risk, engendering adverse outcomes such as low birth weight, early weaning, increased infant mortality, spontaneous miscarriages, and obstetric complications(5). These results emphasize the importance of healthcare service preparedness to address the health-related consequences of natural disasters.

\section{Longitudinal care, routine care, and healthcare services}

In all six families, similar narratives emerged regarding the maintenance of regular care routines such as immunizations, medical evaluations, and regular clinical examinations primarily intended for monitoring child health before the disaster. Due to the disaster, however, the local basic health units (BHUs) remained closed for a long period, and this difficulty of access interfered with routine care after the disaster. The families also mentioned other factors that hindered their access to healthcare services that were associated with rural environments such as the distance of some houses from the municipality and the lack of transportation or the poor road conditions during the rainy season. In addition, other factors were related to the functioning of the local BHUs such as insufficient information from the staff about the care provided and even macro factors such as deficiencies in solving the other levels of public healthcare, which led to searches for private medical services. 
One identified characteristic referred to in the narratives reveals the role of women in the organization of care routines when someone becomes ill. Women who do not know how to drive a car are unable to travel to the $\mathrm{BHU}$ and participate in other activities related to health promotion and receive greater access to services. However, these women search for information from the staff or from other network services when they need a solution because they are more connected with the $\mathrm{BHU}$.

The data also revealed that family care routines are adapted when members become ill; in some cases, however, less flexibility exists due to harsh work routines after the disaster, particularly when trips to the BHU or hospital/emergency room are needed during severe situations or the weekends. The narrative below illustrates this dynamic:

My little girl was sick this week, and so was my 6-year-old son. She was losing blood through her nose. I thought it could be something serious, but it was because of the flu [...]. My husband left his work and took my son to the doctor because both of us cannot go. Then, because I don't know how to drive, he was the one who took him early in the morning [...]. At $6 \mathrm{am}$, he had to go there to make an appointment with the doctor because they do not take appointments over the phone, and this is difficult for us [...]. This was out of our routine, but otherwise they hardly get sick. [...] I even think they should make an exception for people who work, but they do not take appointments (-). Then, we had to leave work to make an appointment at 6 am, but you have to be there at 5:30 am, otherwise you cannot get an appointment $[. .$.$] . We get a work excuse document to show at$ the company, and we don't lose the day (-), but the boss lets us recover the hours so as not to lose wages [...]. They serve us very well at the $\mathrm{BHU}$; in the beginning, they even sent us to see a psychologist [...] but not anymore (-); this hasn't happened since last year (MF5).

The families' narratives suggest situations in which professional care was sought across the different healthcare services such as hospitals, emergency rooms, and doctors' offices. The route traversed by the families who sought care, especially in situations of acute child illnesses, is commonly expressed in various contexts, regardless of the disaster because it is associated with the parents' beliefs regarding the severity of their child's illness and the difficulty of accepting the help of other professionals (except medical consultations) to resolve the problem at the $\mathrm{BHU}^{(19)}$. Thus, it is important to consider that a mismatch often exists between the routines of the families and the $\mathrm{BHU}$, which prolongs the search for care in emergency rooms and hospitals.
The observations from the mothers denoted that professional care sensitivity and, in some cases, ability, implied acceptable service to families in situations aggravated by exposure to a disaster. The narrative below describes the perception regarding the lack of professional preparedness to meet the changing needs of care after the disaster:

[They] changed because they had to learn to deal with people's emotions (-). We observed that when the weather was bad or when it rained more; the clinic has more people then. The people go there saying that it hurts here, it hurts there; if they start talking to these people, they realize that it is all emotional: it's fear, it's concern. There was a great increase in the number of referrals to the psychologist, mainly adults, and the use of controlled medications. In fact, it is necessary to find a way to treat the psyche without the person knowing that this is being done, especially for older people, you know? For example, imagine if the doctor tells you need a psychologist! He [the doctor] should ask the nurse to guide this indication; otherwise people will pass by, or they won't go. The elderly are still afraid that this [treatment] is for crazy people who have mental problems or something, so it should be a treatment in which the person gets involved without them knowing until a certain time. I think this is still missing (...) (MF4).

Thus, the care and support for individuals, families, and communities should exist in throughout the whole cycle: before the disaster, during the acute phase, after the acute phase, and recovery. Population empowerment should be a strategy for disaster preparedness that provides opportunities to understand vulnerabilities and promote cohesion and community support(20-21).

Perceptions regarding the health-disease process of certain family members who became ill during the disaster were interpreted with regard to the consequences of life changes and their effect on the family routine. The health of the family is guaranteed via the promotion of routines and rituals that encourage interaction, cohesion, socia participation in rights advocacy, improvements in quality of life, and the prevention of new disasters. Daily care not only encourages the development of personal skills in the interactions between parents and children but also builds healthier lifestyles through prevention and the health education of family members.

The support of family healthcare staffs and the employment strategies that assist families in household health production were judged as insufficient or too distant. Furthermore, the system is more complex for those living in rural areas during illness situations that require care. However, these data deserve additional analysis. 


\section{Final Considerations}

The results of the present study contribute to the understanding that natural disasters greatly affect healthcare routines; however, a constant family effort existed to provide the conditions needed to maintain or improve individual health, particularly for children, given their development and future health. In addition, the families reviewed and reassessed routines and rituals based on the new care needs that arose after the disaster and within the context of individual and family development phases.

Thus, the Family Routines and Rituals benchmark supports the understanding of the experiences of families in transition after disasters and helps them to interpret their care needs, using health promotion and a culturally sensitive approach.

More research is needed to understand the experiences and perceptions of nurses and healthcare professionals regarding service needs after a disaster, especially when the local/municipal health infrastructure is affected. This research should specifically explore the roles and functions of nurses in each phase, from before the disaster to the recovery phase.

The theme of natural disasters should be included in the agenda of research groups, the curriculum of technical courses and nursing degrees, and continuing health education cycles where Family Health Strategy (FHS) professionals can exchange experiences, address technical-scientific knowledge deficiencies to work with affected populations, and develop municipal response plans to the events that characterize each region.

\section{References}

1. Pan American Health Organization. Natural disasters: Protecting the public's health. Washington, DC: PAHO; 2000.

2. Ahern M, Kovats RS, Wilkinson P, Few R, Matthies

F. Global Health Impacts of Floods: Epidemiologic Evidence. Epidemiol Rev. 2005;27:36-46

3. Belfer ML. Caring for children and adolescentes in the aftermath of natural disasters. Int Rev Psychiatry. 2006 Dec;18(6):523-8.

4. Tees MT, Harville EW, Xiong X, Buekens P, Pridjian G, Elkind-Hirsch K. Hurricane Katrina-Related Maternal Stress, Maternal Mental Health, and Early Infant Temperament. Matern Child Health J. 2010;14(4):511-8. 5. Callaghan WM, Rasmussen AS, Jamieson DJ, Ventura SJ, Farr SL, Sutton PD, et al. Health Concerns of Women and Infants in Times of Natural Disasters: Lessons
Learned from Hurricane Katrina. Matern Child Health J. 2007 Jul;11(4):307-11

6. Rowe $C L$, Liddle $H A$. When the levee breaks: treating adolescents and families in the aftermath of Hurricane Katrina. J Marital Fam Ther. 2008 April;34(2):132-48.

7. Polusny MA, Ries BJ, Schultz JR, Calhoun P, Clemensen L, Johnsen IR. PTSD Symptom Clusters Associated With Physical Health and Health Care Utilization in Rural Primary Care Patients Exposed to Natural Disaster. J Traumatic Stress. 2008 Feb;21(1):75-82.

8. Cloyd E, Dyer CB. Catastrophic Events and Older Adults. Crit Care Nurs Clin N Am. 2010;22(4)501-13.

9. Chang L, Chen HH, Cheng C, Chang S. A comprehensive health promotion program for disaster reconstruction families in Taiwan [abstract]. In: Anais of 20th IUHPE World Conference on Health Promotion; 2010 Jul 11-15; Geneva, Switzerland. [acesso 14 jul 2011]; Disponível em: http:// www.iuhpeconference.net/downloads/en/Records/ 100806_Geneva2010_abstracts.pdf

10. Lapitan JM, Ukai T, Steffens C, Armada F. Assessing health facilities' preparedness for disasters in cities: a case study of two hospitals in Kobe, Japan [abstract]. In: Anais of 20th IUHPE World Conference on Health Promotion, Geneva, Switzerland. [acesso 25 mar 2013 25]; Disponível em: http://www.iuhpeconference.net/downloads/ en/ Records/100806_Geneva2010_abstracts.pdf

11. Dash SR, Kanungo I. Challenges for hygiene and health promotion - a study in flood affected areas of Jagatsinghpur district in Orissa, India [abstract]. In: Anais of 20th IUHPE World Conference on Health Promotion, Geneva, Switzerland. [acesso 25 mar 201325]; Disponível em: http://www.iuhpeconference.net/downloads/en/ Records/100806_Geneva2010_abstracts.pdf

12. Roth P, Simanello MA. Family Health promotion during Transitions. In: Bomar PJ. Promoting Health in Families. Applying Family Research and Theory to Nursing Practice. 3rd New York: Elsevier; 2004. p. 477-506.

13. Denham S. Relationships between Family Rituals, Family Routines, and Health. J Fam Nurs. 2003; 9(3):305-330.

14. Boehs $A E$, Grisotti $M$, Aquino MDW. The routine of families with nursing infants. Rev. Latino-Am. Enfermagem. set-out 2007;15(5):902-8.

15. Cerveny CMO, Berthoud CM. Família e Ciclo Vital. Nossa realidade em pesquisa. São Paulo: Casa do Psicólogo; 1997.

16. Schütze F. Pesquisa biográfica e entrevista narrativa. In: Weller V, Pfaff N. Metodologias da Pesquisa Qualitativa em Educação. Teoria e Prática. Petrópolis: Vozes; 2010. p. 211-22. 
17. Fiese BH. Family Routines and Rituals. New Haven (EN): Yale University; 2006.

18. Mendez TB. Disaster Planning for Vulnerable Populations: Mental Health. Crit Care Nurs Clin N Am. 2010;22(4):493-500.

19. Oliveira BRG, Collet N, Mello DF, Lima RAG. The therapeutic journey of families of children with respiratory diseases in the public health service. Rev. Latino-Am. Enfermagem. maio-jun 2012;20(3):453-61. 20. Badakhsh R, Harville E, Banerjee B. The Childbearing Experience During a Natural Disaster. JOGNN. 2010;39(4):489-97.

21. Deeny P, Vitale CT, Spelman R, Duggan S. Addressing the imbalance: empowering older people in disaster response and preparedness. Int J Older People Nurs. 2010;5(1):77-80. 